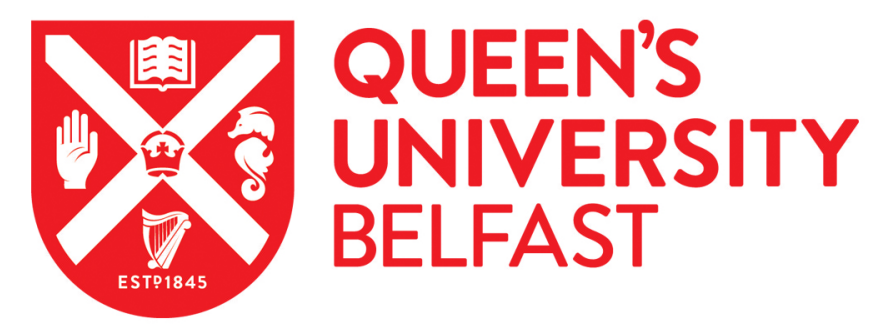

\title{
Verbal and visuospatial working memory in immersion-educated bilingual children
}

McVeigh, C., Wylie, J., \& Mulhern, G. (2017). Verbal and visuospatial working memory in immersion-educated bilingual children. International Journal of Bilingual Education and Bilingualism.

https://doi.org/10.1080/13670050.2016.1271769

\section{Published in:}

International Journal of Bilingual Education and Bilingualism

\section{Document Version:}

Peer reviewed version

\section{Queen's University Belfast - Research Portal:}

Link to publication record in Queen's University Belfast Research Portal

\section{Publisher rights}

(C) 2017 Informa UK Limited, trading as Taylor \& Francis Group

This work is made available online in accordance with the publisher's policies.

\section{General rights}

Copyright for the publications made accessible via the Queen's University Belfast Research Portal is retained by the author(s) and / or other copyright owners and it is a condition of accessing these publications that users recognise and abide by the legal requirements associated with these rights.

Take down policy

The Research Portal is Queen's institutional repository that provides access to Queen's research output. Every effort has been made to ensure that content in the Research Portal does not infringe any person's rights, or applicable UK laws. If you discover content in the Research Portal that you believe breaches copyright or violates any law, please contact openaccess@qub.ac.uk. 
Verbal and visuospatial working memory in immersion-educated bilingual children

Working memory is a recognised component of executive function and has undergone scrutiny in terms of bilingual and monolingual performance comparisons. Research to date, however, has not consistently replicated the presence of bilingual advantage. The present study examined short-term (STM) and working memory (WM) in immersioneducated children and a matched group of English monolingual controls. One hundred and twenty one children participated, and differences in performance were examined in two age groups (7 and 9 years). Children performed two STM (digit recall, mazes memory) and four WM tasks (listening recall, counting recall, backwards digit recall, $\mathrm{Mr}$ $\mathrm{X})$. Results indicated largely equivalent performance on the STM and WM tasks administered. Verbal STM and WM performance was then examined within the bilingual sample, which performed the tasks in both English (L1) and Irish (L2). Results indicated largely equivalent performance across languages for both age groups, with language dominance effects emerging in one verbal WM task (listening recall) only. Overall, our results suggest that bilingualism does not confer advantages for working memory. Implications for the assessment of STM and WM in bilingual children participating in a full immersion education programme are discussed.

Keywords bilingualism, working memory, short term memory, visuospatial, verbal, immersion education. 


\section{Verbal and visuospatial working memory in immersion-educated bilingual children}

\section{Introduction}

Across the world large numbers of children are educated in immersion settings where the language of school differs from the home language, an experience which allows children to develop ability in two languages. Given changing demographics in many areas of the world, and the growing interest in the consequences of bilingualism across the lifespan, researchers recognise the potential of studying immersion-educated children. As Hansen et al. (2016) acknowledge, there is a clear need for research on how the immersion method of acquiring bilingualism affects the development of cognitive skills and abilities.

It is widely accepted that bilingualism can affect cognitive development. For more than three decades researchers have identified so-called positive and negative effects of bilingualism on a range of cognitive and linguistic skills. Such effects are purported to result from the monitoring and selection that are required for speech comprehension (e.g. Marian and Spivey 2003), and production (e.g. Kroll, Bobb, and Wodniecka 2006) as a result of the simultaneous activation of a bilingual's two languages. Cognitive advantages for bilingual children have been found consistently in tasks of metalinguistic awareness (Ben-Zeev 1977; Galambos and Goldin-Meadow 1990) and in tasks requiring cognitive flexibility and divergent thinking (Adi-Japha, Berberich-Artzi and Libnawi 2010; Ricciardelli 1992). Bialystok (2015) notes how these advantages can be attributed to an awareness of abstract language structure, reflecting cognitive ability more so than linguistic processing, and that bilinguals perform particularly well in task conditions requiring resolution of competing stimuli. In addition, cognitive advantages have been found for children and adults in tasks involving controlled attention, monitoring goal-relevant information and inhibition of non- 
goal related information (e.g. Bialystok and Feng 2009; Colzato et al. 2008; Emmorey, Luk, Pyers and Bialystok 2008). All of these cognitive processes have been suggested to be indicators of executive function (Miyake et al. 2000), with bilingual advantage on such tasks attributed to the experience of managing two languages (Bialystok 2009) or, more specifically, to the continuous selection and processing of lexical information in two languages (Ratiu and Azuma 2015).

Executive function has been suggested to consist of inhibition, updating (or working memory) and shifting (Miyake and Friedman 2012; Miyake et al. 2000). Whilst research has found some evidence of bilingual advantage on tasks of inhibition (Bialystok, Craik and Luk 2012; Bialystok, Craik and Luk 2008; Colzato et al. 2008; although this is disputed by Duñabeitia et al. 2015; Paap and Greenberg 2013; Paap, Johnson and Sawi 2015) and shifting (Prior and MacWhinney 2010; Qu et al. 2015), findings of bilingual advantage on working memory tasks have not been consistently replicated. An important factor here might be the nature of the task. Baddeley's well-established working memory model (Baddeley 2000; Baddeley and Hitch 1974; Baddeley, Allen and Hitch 2011) makes a distinction between simple storage storage plus processing tasks. The former are known as short-term memory tasks while the latter as working memory tasks. In their recent review of executive function impairments, Synder, Miyake and Hankin (2015) distinguished between working memory manipulation and working memory maintenance when identifying common measures. Thus, short term memory may be considered part of the executive system, albeit of a lower level of complexity, and relying less on the central executive.

Our particular focus in this study is the effect of bilingualism, as acquired through immersion education, on working memory. Studies indicating bilingual advantage for children on working memory (WM) and short term memory (STM) tasks include Blom et al. 
(2014), Feng, Diamond and Bialystok (2007) and Calvo and Bialystok (2014), whilst mixed or null findings have been reported by Engel de Abreu (2011), Ratiu and Azuma (2015), Luo, Craik, Moreno and Bialystok (2013) and Bajo, Padilla and Padilla (2000). Furthermore, mixed findings have been indicated on both verbal and visuospatial tasks of WM and STM. A meta-analysis conducted by Adesope, Lavin, Thompson and Underleider (2010) found that bilingualism was associated with greater WM capacity. In contrast, Bialystok (2009) concluded that the WM capacity of bilinguals and monolinguals did not differ, and that the nature of tasks was a key factor in whether or not bilingual advantages would be apparent, with the latter evident only when more demanding tasks requiring greater levels of attentional control (Kane, Bleckley, Conway and Engle 2001) were used. It is important to note, however, that the maintenance and manipulation of information in working memory in bilinguals and monolinguals has received relatively little attention when compared with the body of work involving other executive functions.

Research in this field has previously undergone criticism regarding small sample sizes, construct validity (see Paap and Sawi 2014) and linguistic heterogeneity amongst bilingual participants resulting in difficulty comparing studies (Grosjean 2008) and an unclear picture overall. To address these criticisms in the present study examining WM and STM in bilingual and monolingual children, samples of 55 bilingual and 66 monolingual children were recruited; these sample sizes are greater than those typically reported in studies comparing monolingual and bilingual performance in children or adults on cognitive tasks. The Automated Working Memory Assessment (AWMA; Alloway 2007) used to assess WM and STM is a published assessment used in previous research in this area (e.g. Blom et al. 2014; Engel de Abreu 2011; Soliman 2014). Bilinguals with a similar language background and similar experience of separate language use within their home and school contexts were recruited from the Irish immersion education sector in Northern Ireland in order to satisfy our 
aim of studying bilingual children who had highly similar linguistic experiences in their first (L1) and in their second (L2) languages.

The present study also aimed to examine bilingual children's verbal WM and STM in their L1 and L2. Investigating verbal STM performance in French and English in two samples of bilinguals, Thorn and Gathercole (1999) found no language effect for bilinguals who acquired both languages at the same time (simultaneous bilinguals), but showed a language dominance effect for those who acquired their two languages sequentially. In the present study we anticipated that bilingual children would perform differently on verbalbased tasks of WM and STM depending on the language of testing. Furthermore, in line with both Thorn and Gathercole's (1999) finding that phonological STM operates in a languagespecific way, and with Baddeley's (2003) suggestion that language experience and usage have an effect on performance in verbal tasks, STM and WM task advantage was hypothesised in line with language dominance. Chee, Soon, Li and Pallier (2004) found that language proficiency can impact on verbal and non-verbal WM performance, with differentiated patterns of neural activation indicated in bilinguals with equivalent proficiency and in those with a dominant language. While the children in our study are judged to be balanced and proficient in their two languages for the purposes of accessing the curriculum, their overall linguistic experience is such that they are considered to be dominant in English. Outside of the Irish-speaking (Gaeltacht) regions across the island of Ireland, this is the predominant profile of children attending Irish immersion schools (see Parsons and Lyddy 2016).

To gain a fuller picture of bilingual and monolingual children's cognitive performance, measures of non-verbal IQ and receptive vocabulary were administered. No language group differences were hypothesised for non-verbal IQ in line with the findings of 
Kormi-Nouri et al. (2008) and Engel de Abreu (2011). Also, it was anticipated that bilingual children would control a smaller English vocabulary than their monolingual counterparts (Bialystok, Luk, Peets \& Yang 2010; Oller \& Eilers 2002).

In their review of research on the cognitive development of dual language learners, Barac, Bialystok, Castro and Sanchez (2014) concluded that there is too little research on working memory to permit firm conclusions. Hence, given the mixed and relatively limited nature of international research findings, the study was explorative in terms of bilingual and monolingual performance on STM and WM tasks. For comparisons of L1 and L2 performance on verbal memory tasks, language dominance effects were anticipated in line with children's L1 (English), particularly as task demands increase (i.e. in working memory measures).

\section{Method}

\section{Design}

A between-groups design was used to examine the performance of bilingual children and monolingual children at two age groups on the English language AWMA, Raven's Standard Progressive Matrices (Raven's SPM; Raven 2003), and the Peabody Picture Vocabulary Test (PPVT; Dunn \& Dunn 2007). A repeated measures design was used to examine bilingual children's performance on WM and STM tasks in L1 and L2 using the English and Irish versions of the AWMA.

\section{Participants}


One hundred and twenty one participants were recruited from urban schools in County Antrim, Northern Ireland. All participants attended mainstream education, and had no instances of special educational needs. Children's enrolment in either an Irish-medium or an English-medium school is determined by parental choice.

Fifty five bilinguals (47\% male) were recruited from Irish-medium schools which utilised a full Irish-language immersion method. Schools in the Irish-medium sector in Northern Ireland teach all subjects except English through the medium of Irish, with formal English language teaching commencing in the final term of the third year of school. Unlike in many other immersion education settings worldwide, the full immersion mode (apart from English literacy lessons) is maintained throughout the seven years of primary education.

Questionnaires completed by parents and children revealed that children had L1 English and used mostly English at home. Children therefore were native English speakers with age-appropriate Irish proficiency required to access the same curriculum as monolinguals. Thirty two were categorised as age 7 years from the date of the initial test session $(M=85$ months, $S D=4$ months $)$ and 23 were categorised as age 9 years $(M=108$ months, $S D=5$ months). The younger bilingual group had 7 years of English language experience $(M=7.0 ; S D<0.01)$ and 5 years of Irish $(M=5.0 ; S D=1.08)$. The older bilingual group had approximately 9 years of English language experience $(M=8.9 ; S D=0.29)$ and over 6 years of Irish experience $(M=6.5, S D=1.0)$.

Sixty six monolingual English children (39\% male) were recruited from Englishmedium schools. Thirty four were categorised as age 7 years $(M=85$ months, $S D=3$ months), and 32 were categorised as age 9 years $(M=108$ months, $S D=3$ months $)$. To confirm that children were monolingual, information on languages spoken was requested from the Special Educational Needs Co-ordinator or the child's teacher as well as from the 
child. The younger group had 7 years of English language experience $(M=7.0, S D=0.4)$ and the older group had 9 years of English language experience $(M=9.0, S D=0.3)$. The schools from which the children were recruited were matched on socio-economic status (Department of Education Northern Ireland 2008) on the basis of free school meal uptake (Irish: $31-59 \%, M=44 \%$; English: $33-50 \%, M=40 \%$ ). Percentage uptake of free school meals is commonly used as a proxy for SES in the UK.

\section{Materials}

Receptive vocabulary

The PPVT Fourth Edition, Form A (Dunn \& Dunn 2007) was used as measure of English receptive vocabulary. Standardised scores were based on a mean of 100, and a standard deviation of 15 .

\section{Short-term and working memory}

English and Irish language versions of the AWMA were used to measure verbal and visuospatial STM and WM. The Irish version of the AWMA was created in response to demand from the Irish medium sector across Ireland for assessment tools in Irish and consisted of an Irish language version of the instructions and stimuli contained in the English language version. Creation of the Irish version of the AWMA comprised a multi-stage process. First, the battery was translated into Irish by a professional translator. This version was adapted further following consultation with school principals, teachers and textbook/test developers for the Irish medium education sector. Finally, a small-scale pilot was carried out in order to check that instructions and test items were comprehensible to children. Instructions for all tests were as similar as possible to those in the English version, altered 
only where a direct translation was excessively complex or lengthy in Irish. Unlike English, sentences in Irish take a verb-subject-object structure, rendering some direct translation unsuitable. Of the individual tests, word recall, non-word recall (not used in this study) and listening recall required most adaptation. As in the English version, care was taken to avoid phonological and semantic similarities in multi-item trials. For listening recall, we retained a translation of the English version except where this resulted in longer sentences as a result of syntax differences, when word-length of the to-be-remembered item was inappropriate (greater than two syllables) or where it was judged that children would not be familiar with the vocabulary.

The memory tasks comprised of increasingly difficult levels, with 6 items presented per level. Testing stopped when a child made three errors within a level. To examine differences between monolinguals and bilinguals, analyses were conducted with raw scores on each task. The following tasks were administered:

Word recall task (verbal STM) The participant is aurally presented with a sequence of words to recall in order of presentation. The maximum score is 42 .

Listening recall task (verbal WM) The participant listens to a series of spoken sentences, and verifies the sentence by stating "true" or "false". Once all judgements have been made, recall of the final word of each sentence is required in order of presentation. The maximum score is 36.

Counting recall (verbal WM) Red circles and blue triangles are presented on screen. The participant is initially required to count aloud the number of circles on screen. Once the counting of all sets in a trial has been completed, the child is asked to recall in order how many circles were presented in each set. The maximum score is 42 . 
Backward digit recall (verbal WM) Series of digits are presented aurally and the participant is required to recall these in reverse order of presentation. The maximum score is 36.

Mazes memory (visuospatial STM) A route leading out of a maze is presented on screen for 3 seconds; the participant is required to re-trace the route with their finger in a blank maze. The maximum score is 48 .

Mr. X (visuospatial WM) The task begins with two Mr. X cartoon figures on screen, one wearing a blue hat and one wearing a yellow hat. The child is initially required to identify whether the Mr. X with the blue hat is holding the ball in the same hand as the Mr. X with the yellow hat. During the trials, the Mr. X with the blue hat is presented at different degrees of rotation. The secondary task requires the participant to recall the former location(s) of the ball held by Mr. X with the blue hat. The maximum score is 42 .

Non-verbal IQ

Raven's Standard Progressive Matrices (Raven 2003) were administered in a small group setting to examine non-verbal IQ. Analyses were conducted with raw scores. The maximum score is 60 .

\section{Procedure}

Following approval from the departmental research ethics committee, informed verbal consent was sought from school principals and participating children; parents were asked to provide informed written consent. The monolinguals completed the tests in two sessions. In the first session, the PPVT and AWMA were administered individually. In the second session, monolinguals completed Raven's Standard Progressive Matrices in a small group setting. Tests were administered across three sessions for bilinguals. In the first session, the 
PPVT and AWMA were administered individually. In the second session, bilinguals completed the second version (English or Irish) of AWMA tasks on an individual basis. Raven's Standard Progressive Matrices were completed in a small group setting in a third testing session. In other words, the bilinguals completed the AWMA tasks twice (once in English and once in Irish) and the monolinguals completed these once (English only). Presentation of Irish and English language versions of the AWMA to the bilinguals were counterbalanced and administered at least 7 days apart. For all participants, the individual AWMA tasks were ordered to maximise between-task differences in modality and cognitive demand.

\section{Results}

\section{Non-verbal IQ and receptive vocabulary}

Two-way between-groups ANOVAs were conducted to examine age and language group differences in non-verbal IQ (Raven's SPM) and receptive vocabulary (PPVT). In the Raven's analysis, the sample size was reduced as a discrepancy analysis conducted on the children's scores (in line with the manual guidance) indicated that the total scores were valid for 55 children only. For Raven's SPM, older children scored higher $(M=31.5, S D=8.6)$ than younger children $(\mathrm{M}=21.1, S D=6.0), F(1,62)=29.863, p<.001, \mathrm{\eta}_{\mathrm{p}}{ }^{2}=0.325$. There was no effect of language group and no significant age $\mathrm{x}$ language group interaction. There was a main effect of language group on the PPVT, $F(1,117)=13.85, p<.001, \eta_{\mathrm{p}}{ }^{2}=0.106$ with monolinguals attaining higher scores $(M=99.95, S D=12.06)$ than bilinguals $(M=$ 92.31, $S D=11.87)$. 


\section{Language group and age differences in STM and WM performance}

Table 1 shows the STM and WM task performance of monolingual and bilingual children at ages 7 and 9. Multivariate Analysis of Variance was used to examine differences between bilinguals and monolinguals at age 7 and 9 on six English language measures of the AWMA. There was a significant difference between the age groups, $F(6,112)=10.85, p<.001, \eta_{\mathrm{p}}{ }^{2}=$ 0.37 , and between bilinguals and monolinguals, $F(6,112)=3.29, p=.005, \mathrm{\eta}_{\mathrm{p}}{ }^{2}=0.15$, on the combined dependent variables. There was no interaction. Subsequent investigation focused on age and language group differences on each AWMA task. We computed 2 (age) x 2 (language group) ANOVAS to analyse the potential age and language differences on the six AWMA tasks. In addition, we tested differences between language groups with Bayesian Null Hypothesis Testing (Rouder, Speckman, Sun, Morey and Iverson 2009). A main effect of age was found for listening recall, $F(1,117)=33.70, p<.001, \mathrm{\eta}_{\mathrm{p}}{ }^{2}=0.22$; word recall, $F(1$, $117)=6.75, p=.01, \mathrm{\eta}_{\mathrm{p}}{ }^{2}=0.05$; mazes memory, $F(1,117)=22.67, p<.001, \mathrm{\eta}_{\mathrm{p}}{ }^{2}=0.16$; counting recall, $F(1,117)=36.74, p<.001, \eta_{\mathrm{p}}{ }^{2}=0.24 ; \mathrm{Mr} . \mathrm{X}, F(1,117)=14.76, p<.001$, $\eta_{\mathrm{p}}{ }^{2}=0.11$ and backward digit recall, $F(1,117)=18.15, p<.001, \eta_{\mathrm{p}}{ }^{2}=0.13$. Older children out-performed younger children.

Despite the main effect for language group, the only significant difference was on the mazes memory task, $F(1,117)=12.28, p=.001, \eta_{\mathrm{p}}{ }^{2}=0.095$, where bilinguals scored higher than monolinguals. The Bayesian $t$-test favoured a bilingual advantage (Bayesian $t$-test of the score between groups: $\left.\mathrm{BF}_{10}>12.1\right)$. In order to examine the possibility of a bilingual practice effect, a t-test was conducted to compare the performance of the bilingual children who performed the task in English first with that of the monolinguals. Results indicated no significant difference between the bilingual children who performed the task in English first and the monolinguals on the mazes memory task, $t(91)=1.284, p=.202$ ). The null 
hypothesis was supported by the Bayesian $t$-test (Bayesian t-test of the score between groups: $\left.\mathrm{BF}_{01}>2.07\right)$. There was no difference between language groups for listening recall, $t(119)=$ $-.931, p=.354$ ), and the null hypothesis was supported by the Bayesian $t$-test (Bayesian t-test of the score between groups: $\left.\mathrm{BF}_{01}>3.47\right)$. The language groups did not differ for word recall, $t(119)=-1.70, p=.09)$, and Bayesian $t$-test showed that the null hypothesis was slightly more likely than the alternative one (Bayesian $t$-test of the score between groups: $\left.\mathrm{BF}_{01}>1.4\right)$. The performance of the two language groups did not differ on counting recall, $t(119)=-1.46, p=.15)$, and the null hypothesis was supported by the Bayesian $t$-test (Bayesian t-test of the score between groups: $\mathrm{BF}_{01}>1.98$ ). There was no language group effect on $\mathrm{Mr} \mathrm{X}, t(119)=.715, p=.476)$, and the Bayesian analysis showed that the null hypothesis of no differences between monolinguals and bilinguals was more likely that the alternative (Bayesian $t$-test of the score between groups: $\mathrm{BF}_{01}>4.08$ ). Finally, there was no difference between language groups for backward digit span, $t(119)=-1.397, p=.165)$, and the null hypothesis was favoured over the alternative in the Bayesian $t$-test: $\mathrm{BF}_{01}>2.13$ ).

[Table 1 near here] 


\section{L1 and L2 performance}

Mixed ANOVAs were used to examine language and age differences in bilingual children's performance of the verbal AWMA tasks. Table 2 shows mean scores and standard deviations for tasks completed by the bilinguals in Irish and English. No interaction between age and language of test was found for any task.

Word recall There was a main effect of age, $F(1,53)=5.394, p=.02, \eta_{\mathrm{p}}{ }^{2}=0.101$, with 9-year olds performing better on both versions. Performance on the English and Irish versions did not differ.

Listening recall A main effect of language was found, $F(1,53)=23.825, p<.001, \eta_{\mathrm{p}}{ }^{2}=0.310$, with children performing better in English than in Irish. Older children scored significantly higher than younger children in both languages, $F(1,53)=13.809, p<.001, \mathrm{\eta}_{\mathrm{p}}{ }^{2}=0.207$. The main effect of language was further examined in relation to potential practice effects using paired samples $t$-tests. Results indicate that for those who completed the task in Irish first, there was a significant difference in task performance, $t(27)=-6.497, p<0.001$, with higher performance in English $(M=9.3, S D=$ 2.8) than Irish $(M=5.9, S D=3.4)$. For those who completed the task in English first, findings indicated no significant difference in task performance, $t(26)=-1.341, p=0.192$.

Counting recall On both versions 9-year olds scored higher than 7-year olds, $F(1,53)=8.96, p=$ $.004, \mathrm{n}_{\mathrm{p}}^{2}=0.145$. As with word recall, there was no effect of language.

Backward digit recall There were no main effects for this task.

[Table 2 near here] 


\section{Discussion}

\section{Non-verbal IQ and receptive vocabulary}

Bilingual and monolingual children performed similarly on the test of non-verbal IQ. Engle de Abreu (2011) found equivalent performance of bilingual and monolingual children on a non-verbal intelligence task when tested longitudinally, and findings are in line with international research (e.g. Kormi-Nouri et al. 2008).

The higher levels of English receptive vocabulary among monolinguals are consistent with child studies in this area and some adult studies (e.g. Mahon and Crutchley 2006; Perani et al. 2003). Harley, Hart and Lapkin (1986) found that pupils in the early years of French immersion education scored lower in tests of English than their English-language-educated counterparts, but performed equivalently or better than monolinguals in reading and vocabulary tests in later grades once formal English literacy skills were taught. This highlights the need to consider the number of years' experience with English language education when examining a child's English vocabulary. The absence of an age $\mathrm{x}$ language interaction might indicate that children had insufficient experience with formal instruction in English for equivalent performance in English to be seen. Research involving older immersion-educated and monolingual children could examine whether this pattern of results can also be seen in the Irish-immersion sector.

\section{Bilingual and monolingual differences in STM and WM}

Results indicated largely equivalent performance of bilinguals and monolinguals on verbal and visuospatial tasks of WM and STM. One exception was the finding of bilingual advantage on the mazes memory task, however when this finding was 
further investigated, results indicated no difference between bilinguals who completed the English language AWMA first and monolinguals. Thus, this result could be taken to have arisen from a practice effect.

Our results conflict with those of Soliman (2014) who compared STM and WM performance in Arabic-English bilinguals and matched monolinguals aged 8-12 years. Soliman (2014) reported that bilinguals outperformed monolinguals on listening recall and counting recall, as well as on digit recall, nonword list recall, visual pattern recall, and paired recall. Our results partly align with those of Kaushanskaya, Gross and Buac (2014) who did not find a bilingual advantage in 5-7 year olds for verbal STM (word recall) when comparing monolingual English children with Spanish-English bilinguals enrolled in a dual language immersion program. Unlike them, however, we did not observe an advantage for the bilinguals on verbal WM (listening span). In a further study of 5-7 year old Spanish-English bilinguals and English monolinguals, however, Buac, Gross and Kaushanskaya (2016) reported that monolinguals outperformed bilinguals on measures of short-term memory but not working memory. This profile of results exemplifies the challenges associated with working in bilingual settings where subtle differences relating to participants, tasks or data analysis can lead to inconsistencies, especially if effect sizes are small (Paap 2014; Valian 2015).

\section{Performance in L1 and L2}

We used the four verbal tasks (word recall, listening recall, counting recall, backward digit span) to investigate performance in L1 and L2, with findings from one task only - listening recall - supporting the hypothesis regarding language dominance. Of the 
four tasks, it is widely agreed that word recall is a measure of verbal short-term memory. There is also a general consensus that counting recall and listening recall are verbal working memory measures. For the remaining task, backward digit span, researchers have differing views regarding its status as a short-term or working memory measure. For example, St Clair-Thompson (2010) proposed that reverse digit span taps working memory in children but short-term memory in adults while Engle, Tuholski, Laughlin, and Conway (1999) hold the position that it is a measure of short-term memory for all ages. More recently, St Clair-Thompson and Allen (2013) concluded from a dual-task investigation that forward and backward digit recall tasks appear to be measures of simple span (i.e. STM), at least in young adults. Given the age of our participants, and in line with Alloway, Gathercole and Pickering (2006), we view backward digit span as a verbal working memory task, here comparing it with our two other verbal WM measures.

The children obtained similar scores on the English and Irish versions of word recall (verbal STM). Given their full immersion experience in school, they have significant exposure to both languages on a daily basis, and there is little reason to predict that simple storage should be enhanced in one language over the other when children have adequate language-specific knowledge. Of the three verbal WM tasks, the highest scores were observed for counting recall. Despite its processing (manipulation) and storage (maintenance) demands, it might be argued that this task is relatively easy due to the highly automatized nature of counting (Danahy, Windsor and Kohnert 2007), and this same argument would hold true for our participants in their dominant and non-dominant languages, given their experience of both languages over several years. Scores on the English and Irish versions were very similar for 
backward digit recall for both age groups. As with counting recall, we suggest that the nature of the material to be processed and recalled is sufficiently familiar and automatized to render equivalent performance for the dominant and non-dominant languages. The remaining verbal WM task, listening recall, was the most challenging for participants with lower scores obtained across both age groups and languages than for the other measures (though not significantly worse than for backward digit span). In line with our predictions, superior performance in English, the dominant language, was observed for the younger and older children. While it is possible that practice may have had a role in performance of this test, the relatively small sample sizes at this stage of the analysis limit our ability to speculate on the effect of practice. Future research should investigate the effect of repeated (L1 and L2) test administration on performance.

Harris and colleagues (1995) found that when scores on a simple span (STM) and complex span (WM) task performed in the dominant language were compared, language-dominant bilinguals did not differ from balanced bilinguals. Using a verbal STM task, Thorn and Gathercole (1999) found a language effect for sequential bilinguals, but equivalent performance for simultaneous bilinguals. While the present finding of better performance on the English version of listening recall supports the suggestion of some degree of language dominance impacting on verbal WM performance, the overall finding of largely equivalent performance on two out of three verbal WM tasks indicates balanced proficiency in both languages. Previous research has highlighted the impact of language proficiency on task performance in a given language (Kempert, Saalbach and Hardy 2011; Marian and Fausey 2006). Our finding of no language-based differences on two verbal WM tasks could be 
interpreted to indicate that Irish is not a 'weak' second language, with children in this context proficient with L2 due to early exposure and extensive usage in immersion education. While this argument holds for the tasks where the language can be considered highly familiar and automatized, we conclude that our bilinguals, despite several years' experience with their second language, exhibit language dominance in tasks that are more demanding in terms of linguistic and cognitive processing.

\section{Implications for teaching and assessment}

We turn now to consider what our results might mean for those working with children in immersion settings. Questions relating to the appropriateness of testing children in their L1 or L2 are paramount for teachers, educational psychologists, researchers and parents. Within the context of our research - where children have daily, sustained exposure to the L2 through a full immersion model - we contend that verbal shortterm memory can be assessed in either language, providing that stimuli have been carefully selected and that robust, normative data are available on the target bilingual population to facilitate the identification of strengths and difficulties. For verbal working memory, a more cautious approach is needed. Where the verbal demands of the task involve familiar, highly automatized stimuli such as numbers, L1 or L2 administration is likely to result in similar outcomes. In contrast, where the processing and storage demands are high, as is the case with listening recall, our findings lead us to suggest that children will obtain higher scores in their L1. We concur with Olsthoorn, Andringa and Hulstijn (2014) who pointed out that many verbal working memory tasks tap into long-term memory for linguistic knowledge as well as working memory per se, making them potentially easier for those more familiar with the language. Finally, our conclusions appear to be at odds with those 
of Buac, Gross and Kaushanskaya (2016) who suggested that the use of working memory, rather than short-term memory tasks might reduce assessment bias in the context of bilingualism.

\section{Summary and conclusions}

Using verbal and visuospatial tasks we examined short-term and working memory performance in bilingual and monolingual children. Verbal STM, verbal WM, visuospatial STM and visuospatial WM performance was similar in the two language groups, regardless of age. We suggest that when children are balanced in terms of their bilingualism, short-term and working memory assessment can take place in either language. As noted above, however, caution may be needed when using tasks with greater linguistic demands (e.g. listening recall).

Looking beyond short-term and working memory, biliteracy and dual language education have been suggested to potentially impact on cognitive control (Kirk, Fiala, Scott-Brown and Kempe 2014). As research for the single mechanism or multiple mechanisms underlying superior executive function (Valian 2015) progresses, there is a clear need to expand this research to include immersioneducated bilinguals outside of Canada and North America. Given that previous research in this field has been criticised for sample sizes, construct validity and linguistic heterogeneity (e.g. Paap and Sawi 2014), it may be noted that the present findings were obtained in a study involving a bilingual group of children with similar language experience in their L1 as well as in their L2, a standardised and commonly used working memory assessment, and larger group sizes than is typical in the domain. 
In conclusion, our investigation adds to the 'handful' of studies that have investigated working memory in bilinguals (Barac et al. 2014). Like Hansen et al. 2016, we aimed to contribute to the limited body of research on the cognitive consequences of L2 immersion education. Our findings lend support to Bialystok's (2009) view that there is little evidence that bilingualism is related to the development and functioning of memory in general, and working memory in particular. As working memory is suggested to comprise one of the executive functions (Miyake et al. 2000; Bialystok 2015), our results are in keeping with those of other researchers who have examined cognitive differences between bilinguals and monolinguals (e.g. Antón et al. 2014; Paap and Greenberg 2013; Prior and MacWhinney 2010) and with Paap and Greenberg's (2013) suggestion that there is no coherent evidence for a bilingual advantage in executive processing. We recognise, however, that some studies (e.g. Kausanskaya et al. 2014) have identified bilingual advantage for verbal working memory; such contradictory findings simply serve to underline the need for further research in a range of bilingual environments. 


\section{References}

Adesope, Olusola O., Tracy Lavin, Terri Thompson, and Charles Ungerleider. 2010. "A systematic review and meta-analysis of the cognitive correlates of bilingualism." Review of Educational Research 80 (2): 207-245.

Adi-Japha, Esther, Jennie Berberich-Artzi, and Afaf Libnawi. 2010. "Cognitive flexibility in drawings of bilingual children." Child Development 81 (5): 1356-1366.

Alloway, Tracey Packiam. 2007. “Automated working memory assessment”. UK: Pearson Assessment.

Alloway, Tracy Packiam, Susan Elizabeth Gathercole, and Susan J. Pickering. 2006. "Verbal and visuospatial short-term and working memory in children: Are they separable?" Child Development, 77 (6): 1698-1716.

Antón, Eneko, Jon A. Duñabeitia, Adelina Estévez, Juan A. Hernández, Alejandro Castillo, Luis J. Fuentes, Douglas J. Davidson, and Manuel Carreiras. 2014. "Is there a bilingual advantage in the ANT task? Evidence from children." Frontiers in Psychology 5: 398.

Antón, Eneko, Yuriem Fernández García, Manuel Carreiras, and Jon Andoni Duñabeitia. 2016. "Does bilingualism shape inhibitory control in the elderly?" 
Journal of Memory \& Language 90:147-160

Baddeley, A. 2000. "The episodic buffer: a new component of working memory?" Trends in Cognitive Sciences 4(1): 417:423.

Baddeley, Alan D. 2003. "Working memory and language: An overview." Journal of Communication Disorders 36 (3): 189-208.

Baddeley, A.D. \& Graham J. Hitch. 1974. "Working memory." The Psychology of Learning and Motivation 8: 47-89.

Baddeley, A.D. Richard Allen \& Graham Hitch. 2011. "Binding in visual working memory: the role of the episodic buffer." Neuropsychologica 49(6): 1393-1400.

Bajo, María Teresa, Francisca Padilla and Presentación Padilla. 2000.

"Comprehension processes in simultaneous interpreting". In Translation in context, edited by Chesterman, 
Barac, Raluca, Ellen Bialystok, Dina C. Castro and Marta Sanchez. 2014. "The cognitive development of young dual language learners: A critical review." Early Childhood Research Quarterly 29 (4): 699-714.

Ben-Zeev, Sandra. 1977. "The influence of bilingualism on cognitive strategy and cognitive development." Child Development 48: 1009-1018.

Bialystok, Ellen. 2015. "Bilingualism and the development of executive function: the role of attention." Child Development Perspectives 9 (2): 117-121.

Bialystok, Ellen. 2009. "Bilingualism: The good, the bad, and the indifferent." Bilingualism: Language and Cognition 12 (1): 3-11.

Bialystok, Ellen, and Xiaojia Feng. 2009. "Language proficiency and executive control in proactive interference: Evidence from monolingual and bilingual children and adults." Brain and Language 109 (2): 93-100.

Bialystok, Ellen, Fergus I.M. Craik, and Gigi Luk. 2012. "Bilingualism: consequences for mind and brain." Trends in Cognitive Sciences 16 (4): 240-250. 
Bialystok, Ellen, Fergus I.M. Craik, and Gigi Luk. 2008. "Cognitive control and lexical access in younger and older bilinguals." Journal of Experimental Psychology: Learning, Memory, and Cognition 34 (4) : 859.

Bialystok, Ellen, Gigi Luk, Kathleen F. Peets, and Yang, Sujin. 2010. "Receptive vocabulary differences in monolingual and bilingual children." Bilingualism: Language and Cognition 13 (4): 525-531.

Blom, Elma, Aylin C. Küntay, Marielle Messer, Josje Verhagen, and Paul Leseman. 2014. "The benefits of being bilingual: Working memory in bilingual Turkish-Dutch children." Journal of Experimental Child Psychology 128: 105-119.

Buac, Milijana, Megan Gross, Margarita Kaushanskaya. 2016. "Predictors of processing-based task performance in bilingual and monolingual children." Journal of Communication Disorders 62: 12-29.

Calvo, Alejandra, and Ellen Bialystok. 2014. "Independent effects of bilingualism and socioeconomic status on language ability and executive functioning." Cognition 130 (3): 278-288. 
Chee, Michael W.L., Chun Siong Soon, Hwee Ling Lee, and Christophe Pallier. 2004. "Left insula activation: A marker for language attainment in bilinguals." Proceedings of the National Academy of Sciences of the United States of America 101 (42): 1526515270.

Colzato, Lorenza S., Maria Teresa Bajo, Wery van den Wildenberg, Daniela Paolieri, Sander Nieuwenhuis, Wido La Heij, and Bernhard Hommel. 2008. "How does bilingualism improve executive control? A comparison of active and reactive inhibition mechanisms." Journal of Experimental Psychology: Learning, Memory, and Cognition 34 (2): 302-.

Danahy, Kerry, Jennifer Windsor, and Kathryn Kohnert. 2007. "Counting span and the identification of primary language impairment." International Journal of Language \& Communication Disorders 42 (3): 349-365.

Department of Education Northern Ireland. 2008. "Primary schools data 2008/2009". Retrieved from http://www.deni.gov.uk/index/32statisticsandresearch_pg/32statistics_and_research_s tatistics_on_education_pg/statistics_and_research_-_statistics_on_educationschool_meals.htm. 
Dunn, Lloyd M., and Douglas M. Dunn. 2007."Peabody Picture Vocabulary Test, fourth edition (PPVT $\left.{ }^{\mathrm{TM}}-4\right)$." Johannesburg: Pearson Education.

Duñabeitia, Jon Andoni, and Manuel Carreiras. (2015). "The bilingual advantage: acta est fabula?" Cortex, 73, 371-372.

Duñabeitia, Jon Andoni , Juan Andrés Hernández, Eneko Antón, Pedro Macizo, Adelina Estévez, Luis J. Fuentes, and Manuel Carreiras. (2014). "The inhibitory advantage in bilingual children revisited: myth or reality?" Experimental Psychology, 61 (3): 234 251.

Emmorey, Karen, Gigi Luk, Jennie E. Pyers, and Ellen Bialystok. 2008. "The source of enhanced cognitive control in bilinguals: Evidence from bimodal bilinguals." Psychological Science 19 (12): 1201-1206.

Engel de Abreu, Pascale M.J. 2011. "Working memory in multilingual children: Is there a bilingual effect?" Memory 19 (5): 529-537.

Engle, Randall W., Stephen W. Tuholski, James E. Laughlin, and Andrew R.A.

Conway. 1999. "Working memory, short-term memory, and general fluid 
intelligence: a latent-variable approach." Journal of Experimental Psychology: General 128 (3): 309-331.

Feng, Xiaojia, Adele Diamond and Ellen Bialystok. 2007. "Manipulating information in working memory: An advantage for bilinguals. Poster presented at the biennial meeting of the Society for Research in Child Development, Boston, MA.

Galambos, Sylvia Joseph, and Susan Goldin-Meadow. 1990. "The effects of learning two languages on levels of metalinguistic awareness." Cognition 34 (1): 1-56.

Grosjean, François. (2008). "Studying bilinguals”. Oxford: Oxford University Press.

Hansen, Laura Birke, Pedro Macizo, Jon Andoni Duñabeitia, David Saldana, Manuel Carreiras, Luis J. Fuentes, and M.Teresa Bajo. 2016. "Emergent bilingualism and working memory development in school aged children." Language Learning 66(2): $51-75$.

Harley, Birgit, Douglas Hart, and Sharon Lapkin. 1986. "The effects of early bilingual schooling on first language skills." Applied Psycholinguistics 7 (4): 295-321. 
Harris, Josette G. C. Munro Cullum, and Antonio E. Puente. 1995. "Effects of bilingualism on verbal learning and memory in Hispanic adults." Journal of the International Neuropsychological Society 1 (1): 10-16.

Kane, Michael J.M. Kathryn Bleckley, Andrew R.A. Conway, and Randall W. Engle. 2001. "A controlled-attention view of working-memory capacity." Journal of Experimental Psychology: General 130 (2): 169.

Kaushanskaya, Margarita, Megan Gross, and Milijana Buac. 2014. "Effects of classroom bilingualism on task-shifting, verbal memory, and word learning in children." Developmental Science 17 (4): 564-583.

Kempert, Sebastian, Henrik Saalbach, and Ilonca Hardy. 2011. "Cognitive benefits and costs of bilingualism in elementary school students: The case of mathematical word problems." Journal of Educational Psychology 103 (3): 547.

Kirk, Neil W., Fiala, Linda, Scott-Brown, Kenneth C., and Kempe, Vera. 2014. "No evidence for reduced Simon cost in elderly bilinguals and bidialectals." Journal of Cognitive Psychology 26 (6): 640-648. 
Kormi-Nouri, Reza, Razie-Sadat, Shojaei, Sadegheh, Moniri, Ali-Reza, Gholami, AliReza, Moradi, , Saeed, Akbari-Zardkhaneh and Lars-Göran Nilsson. 2008. "The effect of childhood bilingualism on episodic and semantic memory tasks." Scandinavian Journal of Psychology 49 (2): 93-109.

Kroll Judith, Susan Bobb, and Zofia Wodniecka. 2006. "Language selectivity is the exception, not the rule: Arguments against a fixed locus of language selection in bilingual speech." Bilingualism: Language and Cognition 9:119-135.

Luo, Lin, Fergus I.M. Craik, Sylvain Moreno, and Ellen Bialystok. 2013. "Bilingualism interacts with domain in a working memory task: Evidence from aging." Psychology and Aging 28 (1): 28-34.

Mahon, Merle, and Alison Crutchley. 2006. "Performance of typically-developing school-age children with English as an additional language on the British Picture Vocabulary Scales II." Child Language Teaching and Therapy 22 (3): 333-351.

Marian, Viorica, and Caitlin M. Fausey. 2006. "Language-dependent memory in bilingual learning." Applied Cognitive Psychology 20 (8): 1025-1048. 
Marian V, and Michael J. Spivey. 2003. "Competing activation in bilingual language processing: Within- and between-language competition." Bilingualism: Language and Cognition. 6: 97-115.

Miyake, Akira, and Naomi P. Friedman. 2012. "The nature and organization of individual differences in executive functions four general conclusions." Current Directions in Psychological Science 21 (1): 8-14.

Miyake, Akira, Naomi P. Friedman, Michael J. Emerson, Alexander H. Witzki, Amy Howerter, and Tor D. Wager. 2000. "The unity and diversity of executive functions and their contributions to complex "frontal lobe" tasks: A latent variable analysis." Cognitive Psychology 41 (1): 49-100.

Oller, D. Kimbrough, and Rebecca E. Eilers, eds. 2002. Language and literacy in bilingual children. Vol. 2. Clevedon: Multilingual Matters.

Olsthoorn, Nomi M., Sible Andringa, and Jan H. Hulstijn. 2014. "Visual and auditory digit-span performance in native and non-native speakers." International Journal of Bilingualism 18 (6): 663-673. 
Paap, Kenneth R. 2014. "The role of componential analysis, categorical hypothesising, replicability and confirmation bias in testing for bilingual advantages in executive functioning." Journal of Cognitive Psychology 26 (3): 242-255.

Paap, Kenneth R., and Zachary I. Greenberg. 2013. "There is no coherent evidence for a bilingual advantage in executive processing." Cognitive Psychology 66 (2): 232258.

Paap, Kenneth R., Hunter A. Johnson, and Oliver Sawi. 2015. "Bilingual advantages in executive functioning either do not exist or are restricted to very specific and undetermined circumstances." Cortex 69: 265-278.

Paap, Kenneth R., and Oliver Sawi. 2014. "Bilingual advantages in executive functioning: problems in convergent validity, discriminant validity, and the identification of the theoretical constructs." Frontiers in Psychology 5: 1-15.

Parsons, Christine, E., and Fiona Lyddy. 2016. “A longitudinal study of early reading development in two languages: comparing literacy outcomes in Irish immersion, English medium and Gaeltacht schools." International Journal of Bilingual Education and Bilingualism 19(5): 511-519. 
Perani, Daniela, Jubin Abutalebi, Eraldo Paulesu, Simona Brambati, Paola Scifo, Stefano F. Cappa, and Ferruccio Fazio. 2003. "The role of age of acquisition and language usage in early, high-proficient bilinguals: An fMRI study during verbal fluency." Human bBrain Mapping 19 (3): 170-182.

Prior, Anat, and Brian MacWhinney. 2010. "A bilingual advantage in task switching." Bilingualism: Language and Cognition 13 (2): 253-262.

Qu, Li, Joel Jia Wei Low, Ting Zhang, Hong Li, and Philip David Zelazo. 2015. "Bilingual advantage in executive control when task demands are considered." Bilingualism: Language and Cognition: 1-17. DOI: 10.1017/S1366728914000376.

Ratiu, Ileana, and Tamiko Azuma. 2015. "Working memory capacity: is there a bilingual advantage?" Journal of Cognitive Psychology 27 (1): 1-11.

Raven, John C. 2003. Standard Progressive Matrices: Sets A, B, C, D and E. Oxford, UK: Oxford Psychologists Press.

Ricciardelli, Lina A. 1992. "Bilingualism and cognitive development in relation to threshold theory." Journal of Psycholinguistic Research 21 (4): 301-316. 
Rouder, Jeffrey, N., Paul L., Speckman, Dongchu Sun, Richard D.Morey, and Geoffrey, Iverson. 2009. "Bayesian $t$ tests for accepting and rejecting the null hypothesis." Psychonomic Bulletin \& Review 16 (2): 225-237.

Soliman, Abdrabo Moghazy. 2014. "Bilingual advantages of working memory revisited: a latent variable examination." Learning and Individual Differences 32: $168-177$.

St Clair-Thompson, Helen L. 2010. "Backwards digit recall: A measure of short-term memory or working memory?." European Journal of Cognitive Psychology 22 (2): 286-296.

St Clair-Thompson, Helen L., and Richard J. Allen. 2013. "Are forward and backward recall the same? A dual-task study of digit recall." Memory \& Cognition 41 (4): 519-532.

Synder, Hannah, R., Akira Miyake, and Benjamin, L. Hankin. 2015. “Advancing understanding of executive function impairments and psychopathology: bridging the gap between clinical and cognitive approaches." Frontiers in Psychology 6: 328. 
Thorn, Annabel S. C., and Susan E. Gathercole. 1999. "Language-specific knowledge and short-term memory in bilingual and non-bilingual children." The Quarterly Journal of Experimental Psychology: Section A 52 (2): 303-324.

Valian, Virginia. 2015. "Bilingualism and cognition." Bilingualism: Language and Cognition 18 (1): 3-24. 